\title{
SISTEMA PARA AVALIAÇÃO DA QUALIDADE DE PESCADOS
}

\section{SYSTEM TO EVALUATE FISH QUALITY}

\author{
Anita Maria da Rocha Fernandes \\ Professora/Pesquisadora \\ UNIVALI \\ Curso de Ciência da Computação - Centro de Ciências Tecnológicas da Terra e do Mar \\ Rua Uruguai, 458 - Centro - Itajaí SC \\ (0xx47) - 3341-7862 - anita.fernandes@univali.br \\ Maico Tomasi \\ UNIVALI \\ Curso de Ciência da Computação - Centro de Ciências Tecnológicas da Terra e do Mar \\ Rua Uruguai, 458 - Centro - Itajaí SC \\ (0xx47) - 3341-7862 - maikon@univali.br \\ Marcos Luiz Pessatti \\ Professor/Pesquisador \\ UNIVALI \\ Curso de Oceanografia - Centro de Ciências Tecnológicas da Terra e do Mar \\ Rua Uruguai, 458 - Centro - Itajaí SC \\ (0xx47) - 3341-7862 - pessatti@univali.br
}

\section{RESUMO}

Este trabalho descreve o funcionamento do software PAQPesc. Ele tem como funcionalidade principal avaliar a qualidade de pescados. O software utiliza técnicas de inteligência artificial e é construído na linguagem de programação PHP. Ele possui uma interface $w e b$, de forma que possa ser implantado em empresas produtoras ou em mercados pesqueiros, estando disponível aos clientes em estações ou pela Internet. Para o correto funcionamento do sistema, ele deve ser alimentado com os dados dos lotes produzidos e suas respectivas análises de qualidade: química, microbiológica e sensorial. O sistema permite ainda que o usuário solicite um diagnóstico geral da qualidade do pescado, apresentando-o na tela e possibilitando sua impressão. As análises químicas e microbiológicas são realizadas em laboratórios. Estas 
informações oriundas dos laboratórios são incluídas por usuários cadastrados com login e senha, permitindo que usuários cadastrados ou não ao utilizar o sistema possam ter acesso aos dados. As informações referentes às análises sensoriais podem ser incluídas por qualquer pessoa que deseje usar o sistema. Além do diagnóstico, também é possível utilizar o sistema para gerar estatísticas sobre a qualidade dos pescados disponibilizando-as para consulta e impressão.

Palavras-chave: Inteligência Artificial. Sistemas de Informação. Qualidade do Pescado.

\begin{abstract}
The work describes the development of PAQPesc software. It has as main function to evaluate fish quality. The software uses techniques of artificial intelligence and it is built in the PHP programming language. It has a web interface so it can be implanted in producing companies or fish markets and it will be available to the customers in stations or through the Internet. For the correct operation of the system, it must be fed with the data of the produced lots and its respective quality analyses: chemistry, microbiology and sensorial. The system also allows the user requests a general diagnosis of the fish quality, introducing it in the screen and turning possible it's printing. The chemical and microbiology analyses are accomplished in laboratories. The data originated from the laboratories are included in the system by users that are registered since the implantation of the system with login and password turning possible that any person that uses it can consult them. The referring information to the sensorial analyses could be registered by any person that wants to use the system. Besides the diagnosis, the system could also generate statistics about the fish quality providing them for consultation and printing.
\end{abstract}

Key-words: Artificial Intelligence. Information Systems. Fish Quality.

\title{
1. INTRODUÇÃO
}

Os alimentos são a fonte de energia das pessoas e como a população mundial aumenta a cada ano, a indústria alimentícia é um dos ramos que possui um futuro cada vez mais promissor. Simultaneamente a este crescimento, aumenta também a exigência das pessoas por alimentos que sejam saudáveis e possuam boas condições de consumo. Segundo Rocha (1995), a produção proveniente da aqüicultura em nível mundial já corresponde a mais de 20 milhões de toneladas/ano, o que representa uma receita na ordem de US\$ 36 bilhões de dólares. O Brasil encontra-se como $27^{\circ}$ colocado na produção do ramo da aqüicultura e de pescados (MERCADO DA PESCA, [2003?]). Os pescados são avaliados pelos consumidores com uma rigorosidade ainda maior do que muitos outros alimentos, pois estes 
devem estar sempre frescos, com boa aparência e possuir uma qualidade excelente. A avaliação da aparência, do cheiro e até mesmo a avaliação da degustação fazem parte da análise sensorial onde é possível definir a qualidade do pescado através dos órgãos sensoriais humanos. No entanto, não é apenas na análise sensorial que se define a qualidade dos pescados, mas também em uma série de outras variáveis químicas e biológicas que precisam ser analisadas e determinadas para a classificação e identificação do que é apto para consumo ou não.

Com o intuito de auxiliar o gerenciamento da produção e avaliação de pescados, este trabalho descreve a criação e utilização de um sistema baseado em técnicas de IA (Inteligência Artificial) que caracterize os pescados conforme sua qualidade. Esse sistema tem como base o modelo de sistema de avaliação de pescados proposto por Fernandes (2000), o qual utiliza a técnica de sistema especialista para tratar as informações; porém, sua funcionalidade restringe-se apenas ao mexilhão. Já o sistema descrito neste trabalho pode ser utilizado para várias espécies, tais como: peixes de água doce e salgada, camarões, siris, caranguejos, moluscos, bivalves, polvo e lula. Inicialmente a avaliação dos pescados seria personalizada para cada espécie. Após vários estudos em conjunto com especialistas da área de pescados, concluiu-se que a avaliação das variáveis que interferem na qualidade dos pescados deve ser generalizada, pois os limites que determinam a qualidade dos pescados são similares, existindo apenas algumas exceções, onde determinadas espécies possuem variáveis com limites diferentes. Neste caso, o sistema as trata de forma diferente dos outros pescados.

O sistema desenvolvido neste trabalho recebeu o nome de PAQPesc - Sistema para Gerenciamento da Produção e Avaliação da Qualidade de Pescados. Ele pode ser utilizado por empresas do ramo da pesca, agilizando e tornando mais preciso o processo de verificação da qualidade. Também pode influenciar o consumo de pescados sendo utilizado em supermercados onde o próprio consumidor terá a oportunidade de solicitar uma análise do produto que está comprando. Esta última abordagem é possível, pois o supermercado ao comprar o produto pesqueiro recebe as informações provenientes das análises químicas e biológicas. Estas informações alimentam o banco de dados do sistema. O usuário informa as características sensoriais do pescado: cor, cheiro, ou sabor, por exemplo. Estes dados são cruzados com as variáveis das análises biológicas e químicas e como resposta é gerado um diagnóstico do produto que o cliente está adquirindo. 


\section{BASE DE CONHECIMENTO PARA QUALIDADE DE PESCADOS}

Pescado é todo animal que vive normalmente em água doce ou salgada, e que serve para a alimentação. A denominação pescado é bastante abrangente e compreende os peixes, os crustáceos, os moluscos, os anfíbios, os quelônios e os mamíferos de água doce ou salgada, que possam ser utilizados como forma de alimentação humana (KAI, 1988).

Cada vez mais os pescados estão fazendo parte do cardápio das pessoas, e conseqüentemente estão sendo exigidos produtos com qualidade superior. Para que a qualidade dos pescados possa ser avaliada, existem três formas diferentes de análise: sensorial, microbiológica e química (FERNANDES, 2000).

Segundo Fernandes (2000) e Ludorff (1978), a análise sensorial é realizada por pessoas que utilizam os sentidos da visão, olfato, paladar, tato e audição para determinar a qualidade de um produto. No caso dos pescados variáveis como o odor, a textura, o gosto e aparência podem ser utilizados com o intuito de classificá-los como bons para consumo ou não. No sistema desenvolvido são consideradas para análise sensorial as propriedades da aparência dos olhos, do odor e do aspecto exterior do pescado.

A análise microbiológica consiste em avaliar os microrganismos existentes no próprio pescado, além dos que são adquiridos na captura, armazenamento, transporte e consumo podendo muitas vezes conter bactérias prejudiciais para a saúde humana caso estejam fora dos limites (FERNANDES, 2000).

A Tabela 1 apresenta as variáveis pertencentes à Análise Microbiológica, tornando claro o entendimento da sua importância para a qualidade do pescado.

Tabela 1. Variáveis pertencentes à Análise Microbiológica

\begin{tabular}{|c|c|}
\hline Variável & Descrição \\
\hline $\begin{array}{l}\text { Vibrio } \\
\text { parahaemolyticus }\end{array}$ & $\begin{array}{l}\text { É muito encontrado na água do mar, principalmente próximo da costa. Afeta principalmente } \\
\text { a criação do camarão marinho. Se um humano consumir algum tipo de pescado infectado } \\
\text { com esta bactéria, será apresentada gastroenterite aguda. Este quadro é comum após a } \\
\text { ingestão de peixe in natura, mariscos, camarões e ostras contaminadas (AGRIDATA, [200-]). }\end{array}$ \\
\hline Salmonella & $\begin{array}{l}\text { Encontrada em águas poluídas por esgotos ou excreções animais. O cozimento do alimento } \\
\text { destrói o microorganismo, mas se não for completamente destruído poderá causar febre } \\
\text { tifóide, febre entérica e a salmonelose (FERNANDES, 2000). Esta bactéria pode ser } \\
\text { encontrada facilmente em mariscos, mexilhões e ostras (AGRIDATA, [200-]). }\end{array}$ \\
\hline $\begin{array}{l}\text { Staphylococcus } \\
\text { aureus }\end{array}$ & $\begin{array}{l}\text { Bactérias de origem humana que contaminam os pescados na manipulação inadequada } \\
\text { (AGRIDATA, [200-]). As formas de contaminação são por secreção nasal, saliva ou contato }\end{array}$ \\
\hline
\end{tabular}




\begin{tabular}{c|l}
\hline & $\begin{array}{l}\text { com feridas, ações estas provenientes de uma manipulação inadequada dos pescados com } \\
\text { grande falta de higiene. Essas bactérias causam vômitos e diarréias se forem ingeridas por } \\
\text { humanos (FERNANDES, 2000). }\end{array}$ \\
\hline Listeria & $\begin{array}{l}\text { Segundo Fernandes (2000), são bactérias que crescem em condições anaeróbias ou } \\
\text { microaerófilas. Infectam principalmente recém-nascidos, crianças e idosos. }\end{array}$ \\
\hline Fecais & $\begin{array}{l}\text { São bactérias que crescem no trato gastrointestinal dos animais de sangue quente. Fermentam } \\
\text { lactose formando gás (FERNANDES, 2000). }\end{array}$ \\
\hline Mesófilos & $\begin{array}{l}\text { Podem ser encontrados no próprio local da pesca e variam conforme a temperatura local. Em } \\
\text { regiões mais frias a quantidade de mesófilos é menor. Quanto maior for a temperatura, maior } \\
\text { será a quantidade deste microorganismo. Os mesófilos se alojam na carne do pescado, onde } \\
\text { encontram uma situação ideal para viverem e se reproduzirem (OETTERER, [2003?]). }\end{array}$ \\
\hline Psicrófilos & $\begin{array}{l}\text { Segundo Etallcorp (2001), os psicrófilos são microorganismos que crescem em temperaturas } \\
\text { baixas. Encontrados em águas frias, oceanos e regiões polares estes organismos podem } \\
\text { morrer quando expostos à temperatura em torno de 25ㄷ. }\end{array}$ \\
\hline
\end{tabular}

Os valores de cada variável foram estabelecidos com base no conhecimento dos especialistas e em literatura específica da área (FERNANDES, 2000). Tais valores limitantes podem ser diferenciados para algumas espécies, sendo significativos para umas e para outras não. Por exemplo, é importante que um peixe possua um valor máximo de $6,8 \mathrm{pH}$, sendo que valores superiores a este o descartariam acusando má qualidade. No entanto outras espécies não possuem esta restrição para esta variável.

A análise química é importante por que para a mesma espécie, a composição química do pescado pode variar devido a características ambientais, ou abundância e tipo de alimento disponível aos organismos (BRUSCHI, 2001).

A Tabela 2 apresenta as variáveis pertencentes à Análise Química, esclarecendo suas propriedades e sua importância.

Tabela 2. Variáveis pertencentes à Análise Química

\begin{tabular}{c|l}
\hline Variável & \multicolumn{1}{c}{ Descrição } \\
\hline Carboidratos & $\begin{array}{l}\text { Influenciam os resultados da análise sensorial e seu consumo é muito importante para o } \\
\text { organismo humano (FERNANDES, 2000). }\end{array}$ \\
\hline Proteínas & $\begin{array}{l}\text { Segundo Ludorff (1978), as proteínas são muito importantes na alimentação humana e são } \\
\text { encontradas nos pescados em altos teores. Se forem submetidas a grandes alterações de } \\
\text { temperatura alteram a umidade, a textura e o sabor dos pescados. }\end{array}$ \\
\hline Lipídios & $\begin{array}{l}\text { Alguns pescados possuem grande quantidade de lipídios que também são importantes para o } \\
\text { consumo humano. No entanto, no processo de estocagem dos pescados é possível que haja } \\
\text { oxidação dos lipídios, alterando suas propriedades e tornando o produto inapto para o consumo, } \\
\text { podendo causar dando à saúde humana, se consumidos nesta situação (LUDORFF, 1978). }\end{array}$ \\
\hline
\end{tabular}




\begin{tabular}{|c|c|}
\hline Umidade & $\begin{array}{l}\text { Segundo Kai (1988), a umidade ou quantidade de água encontrada no pescado industrializado } \\
\text { pode influenciar o crescimento de bactérias, alterar o volume e o gosto do produto entre outros } \\
\text { aspectos mascarando os resultados da análise sensorial sendo possível até mesmo causar reações } \\
\text { químicas. }\end{array}$ \\
\hline $\begin{array}{l}\text { Resíduo } \\
\text { Mineral }\end{array}$ & $\begin{array}{l}\text { Segundo Fernandes (2000), os resíduos minerais são importantes para o organismo humano e } \\
\text { facilmente encontrados nos pescados. Exemplos de resíduos minerais são: cálcio, fósforo, iodo, } \\
\text { magnésio, sódio e potássio. }\end{array}$ \\
\hline Cálcio & $\begin{array}{l}\text { Encontrado em quantidade significativa nos pescados, o cálcio é a base da estrutura óssea do } \\
\text { corpo humano, sendo necessário um consumo diário em torno de } 1 \text { g/dia (FERNANDES, 2000). }\end{array}$ \\
\hline Fósforo & $\begin{array}{l}\text { Está associado ao cálcio na estrutura óssea e muscular humana. É importante para a formação de } \\
\text { uma dieta saudável e pode ser encontrado em abundância nos pescados (KAI, 1988). }\end{array}$ \\
\hline Magnésio & $\begin{array}{l}\text { Elemento vital aos seres humanos, sua ausência pode ocasionar sérios problemas de saúde. Os } \\
\text { pescados são uma boa fonte deste mineral (FERNANDES, 2000). }\end{array}$ \\
\hline Uréia & $\begin{array}{l}\text { O pescado deve possuir um valor baixo de uréia para ser considerado bom para consumo, pois a } \\
\text { ingestão de grande quantidade deste elemento por humanos pode causar intoxicações, } \\
\text { apresentando reações como falta de coordenação muscular e convulsões (LUDORFF, 1978). }\end{array}$ \\
\hline Iodo & $\begin{array}{l}\text { Essencial ao organismo do homem, o Iodo está distribuído em várias partes do corpo humano. } \\
\text { Segundo Fernandes (2000), os peixes, os crustáceos, as algas e os moluscos marinhos são ricos } \\
\text { neste mineral tornando-se uma interessante fonte produtora. }\end{array}$ \\
\hline Hipoxantina & Esta substância indica o grau de frescor do pescado (KAI, 1988). \\
\hline Histamina & $\begin{array}{l}\text { Substância produzida no processo de decomposição do pescado que pode causar reações alérgicas } \\
\text { nos consumidores (GERMANO, 1998). Quanto menor o índice de histamina, mais fresco o } \\
\text { pescado se encontra. A elevação do seu índice determina deterioração e decomposição do produto } \\
\text { (FERNANDES, 2000). }\end{array}$ \\
\hline Indol & Substância muito importante na caracterização de apodrecimento dos pescados (KAI, 1988). \\
\hline BVT & $\begin{array}{l}\text { As Bases Voláteis Totais são compostas por alterações microbianas do pescado causadas por } \\
\text { aminas biogênicas. Se for consumido um valor alto de BVT, pode ocorrer uma intoxicação no } \\
\text { indivíduo. As bases voláteis estão relacionadas diretamente com a decomposição do pescado } \\
\text { (GERMANO, 1998). }\end{array}$ \\
\hline $\mathrm{PH}$ & $\begin{array}{l}\text { O nível de } \mathrm{pH} \text { deve ser baixo e controlado. Este elemento pode ter sua quantidade alterada se } \\
\text { aumentar o índice de fungos e leveduras na superfície exposta ao ar, causando deterioração do } \\
\text { pescado e aumento do número de bactérias putrificativas. O índice de pH não deve ultrapassar } 6,8 \\
\text { e normalmente se encontra próximo a } 6 \text { (OETTERER, [2003?]). }\end{array}$ \\
\hline
\end{tabular}

A avaliação sensorial determina o grau de frescor do pescado. Este é o método de análise mais econômico, no entanto, esta avaliação pode indicar resultados subjetivos, sendo necessárias outras avaliações (química e microbiológica) para determinar com maior certeza a qualidade e o frescor dos pescados (KAI, 1988). 
Segundo Fernandes (2000) e Ludorff (1978), para ser executada a análise sensorial é preciso formar um grupo de pessoas que farão os experimentos tanto de tato, olfato, degustação e dos outros métodos aplicados. No entanto, no sistema desenvolvido, a análise sensorial tem um enfoque maior nos métodos de avaliação que não necessitem do toque no pescado ou da própria degustação, mas sim em meios que permitam analisar o produto visualmente. Isso ocorre porque muitas vezes o pescado não pode ser tocado ou degustado. Por exemplo, um mercado adquire lotes de pescados com as análises químicas e microbiológicas já realizadas e seus respectivos laudos acompanhando o produto comprado. Passam-se alguns dias e o gerente do mercado decide analisar o produto, o qual já está disposto nos locais visíveis aos clientes. Muitas vezes se torna inviável o gerente ficar tirando amostras dos lotes de pescado e degustá-lo. Este fato também pode ocorrer em uma empresa pesqueira que tenha capturado os peixes, realizados os testes químicos e microbiológicos, e antes de expor o produto a venda decide avaliar a qualidade sensorialmente. Mesmo assim, será incluído no sistema opções de análise sensorial por degustação e pelo tato, para que se forem necessárias estejam prontas para serem utilizadas.

Por este motivo, serão apresentados os aspectos relevantes da análise sensorial, mas com um enfoque maior para os aspectos visuais. Segundo Agridata ([200-]), os aspectos que determinam sensorialmente a qualidade dos pescados estão descrtios na Tabela 3.

Tabela3. Aspectos que determinam sensorialmente a qualidade dos pescados.

\begin{tabular}{|c|c|}
\hline Variável & Descrição \\
\hline $\begin{array}{l}\text { Textura da } \\
\text { Superfície }\end{array}$ & Musculatura resistente, ventre cilíndrico inalterado e não flácido. \\
\hline Pele & $\begin{array}{l}\text { Apresenta coloração variada e brilhante, de acordo com a espécie considerada. Peixes de } \\
\text { tonalidades delicadas podem sofrer descoloração em contato com o gelo, não representando } \\
\text { decomposição. }\end{array}$ \\
\hline $\begin{array}{l}\text { Brilho da } \\
\text { Superfície }\end{array}$ & As escamas devem ser brilhantes e bem aderidas. \\
\hline Guelras & Devem estar úmidas e intactas. \\
\hline $\begin{array}{l}\text { Umidade da } \\
\text { Superfície }\end{array}$ & Quanto mais úmida a superfície estiver, maior o grau de frescor do pescado. \\
\hline Brânquias & $\begin{array}{l}\text { Devem ser vermelhas, de tonalidade variável, mais ou menos intensa, mas sempre } \\
\text { brilhantes. }\end{array}$ \\
\hline Sabor & $\begin{array}{l}\text { É um item a ser analisado por cada indivíduo. As variações podem ser definidas como Muito } \\
\text { Ruim, Ruim, Médio, Bom e Muito Bom. }\end{array}$ \\
\hline Formato do Olho & Devem ser brilhantes e vivos, preenchendo a órbita por completo. \\
\hline
\end{tabular}




\begin{tabular}{l|l} 
Odor & $\begin{array}{l}\text { O cheiro do pescado fresco não causa mal estar; se não estiver mais fresco o odor torna-se } \\
\text { forte e intenso causando incômodo à pessoa que está analisando o produto. }\end{array}$
\end{tabular}

O sistema desenvolvido neste trabalho pode ser implantado em empresas produtoras e em mercados. Nestes dois estabelecimentos normalmente não é possível degustar os pescados e muitas vezes nem tocá-los para evitar a contaminação pelo contato com o corpo humano. Portanto, a análise sensorial não pode ser empregada em todos os seus aspectos neste sistema, mas sim nos aspectos visuais e olfativos. Um outro detalhe a ser considerado é que o sistema também poderá ser utilizado por usuários leigos, que não possuem conhecimento muito aprofundado sobre pescados, não sabendo responder as perguntas do sistema e conseqüentemente perdendo o interesse por ele.

Sendo assim, baseado na bibliografia referenciada (LUDROFF, 1978; KAI, 1988) e em conjunto com especialistas da área de pescados, determinou-se que a análise sensorial analisaria os seguintes aspectos: peixes: cor dos olhos, umidade da superfície, brilho da superfície, sabor, textura e o odor; camarões: brilho da superfície, coloração e sabor; siris e caranguejos: sabor; e moluscos e bivalves: sabor e umidade da superfície.

\section{ORGANIZAÇÃO E ESTRUTURAS DO CONHECIMENTO UTILIZADO}

Para uma correta interpretação dos resultados das análises realizadas nos lotes cadastrados, o sistema utiliza duas técnicas de inteligência artificial: sistema especialista e lógica fuzzy (FERNANDES, 2003; REZENDE, 2003). A primeira é utilizada nas análises química e microbiológica, possuindo árvores de decisões. A segunda é utilizada para interpretar a análise sensorial. Um exemplo da utilização da técnica de sistema especialista está na Figura 1 que apresenta a árvore de decisão da análise microbiológica. O sistema segue os caminhos indicados por esta árvore para tratar os dados informados e gerar uma resposta sobre a qualidade do pescado avaliado.

Como pode ser observado na Figura 1, se alguma variável informada pelo usuário possuir valor fora dos limites permitidos a análise é interrompida e é apresentado o diagnóstico gerado, com a mensagem Amostra Inutilizável (ou seja, a amostra em análise é imprópria para consumo). Se a análise de uma determinada amostra não possuir alguma das informações solicitadas, a árvore se torna flexível, fazendo com que o caminho seja percorrido normalmente e a avaliação microbiológica prossiga. Isso é possível porque o 
sistema interpreta as informações que não são inseridas como ausente. Esta flexibilidade pode ser verificada na representação gráfica da árvore microbiológica e nas regras de produção.

O sistema desenvolvido também possui uma árvore química. Esta por sua vez, possui uma representação e interpretação semelhante à árvore microbiológica, no entanto é bem maior e possui um número expresso de ramificações. Isto ocorre pelo fato de que o sistema considera um número maior de variáveis químicas do que variáveis microbiológicas na avaliação da qualidade dos pescados analisados.

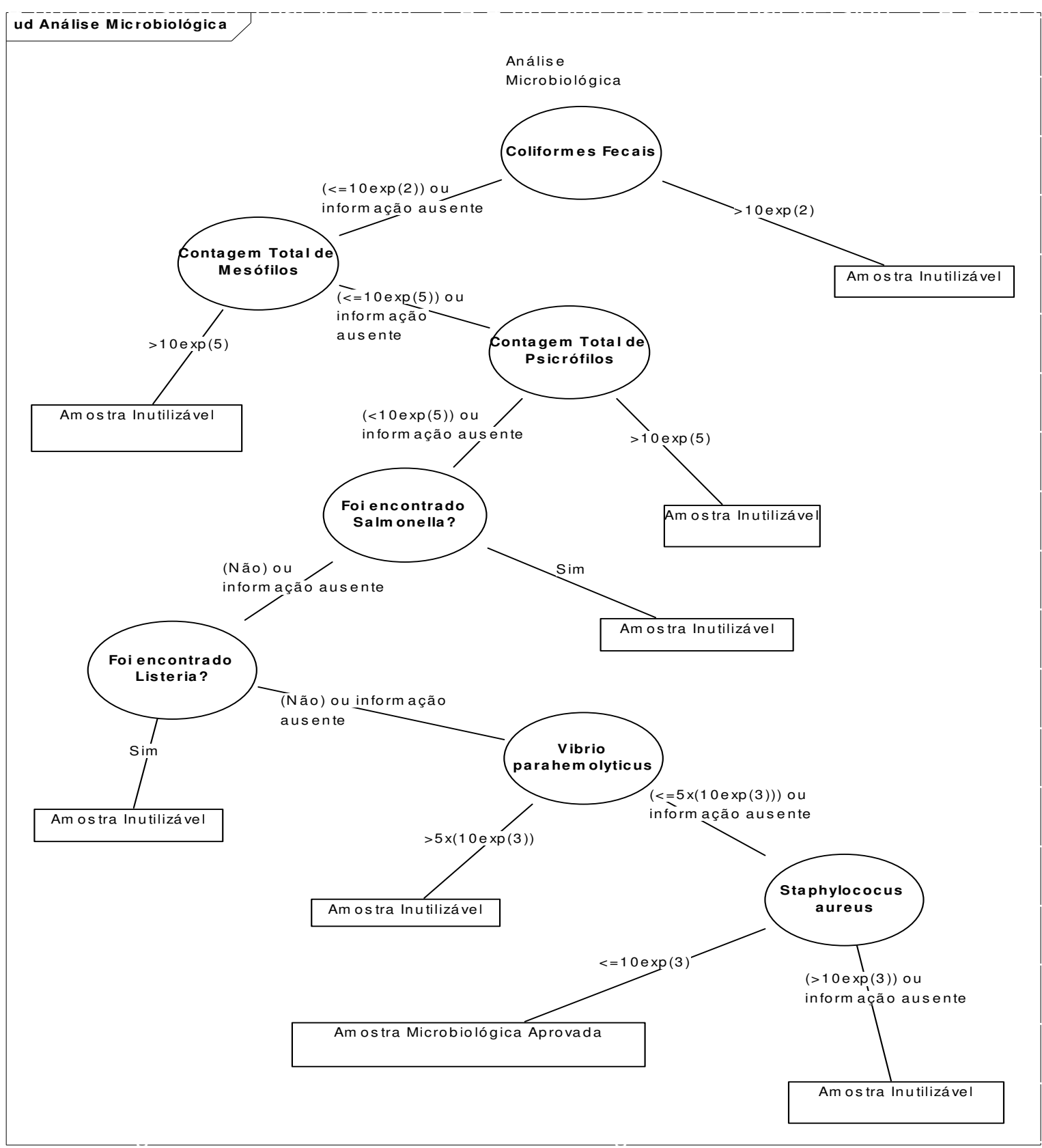


Figura 1. Árvore de Decisão da Análise Microbiológica

No sistema desenvolvido, a lógica fuzzy é utilizada para interpretar os dados das análises sensoriais realizadas. Algumas espécies possuem aspectos diferentes a serem avaliados sensorialmente. A representação dos conjuntos fuzzy que são considerados nos sistema é triangular, portanto a fórmula para calcular as funções de pertinência é $\mathrm{f}(\mathrm{x})=\mathrm{ax}+\mathrm{b}$. A seguir, pode ser observado a Tabela 1 que apresenta as funções de pertinência utilizadas para a análise sensorial dos peixes.

Tabela 3. Tabela das informações que serão utilizadas na análise sensorial dos peixes

\begin{tabular}{|c|c|c|}
\hline Aspecto Avaliado & Variáveis Lingüísticas & Funções de Pertinência \\
\hline $\begin{array}{l}\text { Umidade da } \\
\text { Superfície }\end{array}$ & Seca & $\begin{array}{l}f(x)=x \text { se } x<1 \\
f(x)=1 \text { se } x=1 \\
f(x)=-x+2 \text { se } x>1\end{array}$ \\
\hline $\begin{array}{l}\text { Umidade da } \\
\text { Superfície }\end{array}$ & Média & $\begin{array}{l}f(x)=x-1 \text { se } x<2 \\
f(x)=1 \text { se } x=2 \\
f(x)=-x+3 \text { se } x>2\end{array}$ \\
\hline $\begin{array}{l}\text { Umidade da } \\
\text { Superfície }\end{array}$ & Úmida & $\begin{array}{l}f(x)=x-2 \text { se } x<3 \\
f(x)=1 \text { se } x=3 \\
f(x)=1 \text { se } x>3\end{array}$ \\
\hline Textura & Fofa & $\begin{array}{l}f(x)=x \text { se } x<1 \\
f(x)=1 \text { se } x=1 \\
f(x)=-x+2 \text { se } x>1\end{array}$ \\
\hline Textura & Menos Tensa & $\begin{array}{l}f(x)=x-1 \text { se } x<2 \\
f(x)=1 \text { se } x=2 \\
f(x)=-x+3 \text { se } x>2\end{array}$ \\
\hline Textura & Tensa & $\begin{array}{l}f(x)=x-2 \text { se } x<3 \\
f(x)=1 \text { se } x=3 \\
f(x)=1 \text { se } x>3\end{array}$ \\
\hline Cor dos Olhos & Amarelo & $\begin{array}{l}f(x)=x \text { se } x<1 \\
f(x)=1 \text { se } x=1 \\
f(x)=-x+2 \text { se } x>1\end{array}$ \\
\hline Cor dos Olhos & Dourado & $\begin{array}{l}f(x)=x-1 \text { se } x<2 \\
f(x)=1 \text { se } x=2 \\
f(x)=-x+3 \text { se } x>2\end{array}$ \\
\hline Cor dos Olhos & Prateado & $\begin{array}{l}f(x)=x-2 \text { se } x<3 \\
f(x)=1 \text { se } x=3 \\
f(x)=-x+4 \text { se } x>3\end{array}$ \\
\hline Cor dos Olhos & Branco & $\begin{array}{l}f(x)=x-3 \text { se } x<4 \\
f(x)=1 \text { se } x=4 \\
f(x)=1 \text { se } x>4\end{array}$ \\
\hline Brilho da Superfície & Sem Brilho & $\begin{array}{l}f(x)=x \text { se } x<1 \\
f(x)=1 \text { se } x=1 \\
f(x)=-x+2 \text { se } x>1\end{array}$ \\
\hline Brilho da Superfície & Médio & $\begin{array}{l}f(x)=x-1 \text { se } x<2 \\
f(x)=1 \text { se } x=2\end{array}$ \\
\hline
\end{tabular}




\begin{tabular}{|c|c|c|}
\hline & & $f(x)=-x+3$ se $x>2$ \\
\hline Brilho da Superfície & Brilhante & $\begin{array}{l}f(x)=x-2 \text { se } x<3 \\
f(x)=1 \text { se } x=3 \\
f(x)=1 \text { se } x>3\end{array}$ \\
\hline Sabor & Ruim & $\begin{array}{l}f(x)=x \text { se } x<1 \\
f(x)=1 \text { se } x=1 \\
f(x)=-x+2 \text { se } x>1\end{array}$ \\
\hline Sabor & Ruim & $\begin{array}{l}f(x)=x-1 \text { se } x<2 \\
f(x)=1 \text { se } x=2 \\
f(x)=-x+3 \text { se } x>2\end{array}$ \\
\hline Sabor & Médio & $\begin{array}{l}f(x)=x-2 \text { se } x<3 \\
f(x)=1 \text { se } x=3 \\
f(x)=-x+4 \text { se } x>3\end{array}$ \\
\hline Sabor & Bom & $\begin{array}{l}f(x)=x-3 \text { se } x<4 \\
f(x)=1 \text { se } x=4 \\
f(x)=-x+5 \text { se } x>4\end{array}$ \\
\hline Sabor & Muito Bom & $\begin{array}{l}\mathrm{f}(\mathrm{x})=\mathrm{x}-4 \text { se } \mathrm{x}<4 \\
\mathrm{f}(\mathrm{x})=1 \text { se } \mathrm{x}=5 \\
\mathrm{f}(\mathrm{x})=1 \text { se } \mathrm{x}>5\end{array}$ \\
\hline Odor & Provoca Enjôos & $\begin{array}{l}\mathrm{f}(\mathrm{x})=\mathrm{x} \text { se } \mathrm{x}<1 \\
\mathrm{f}(\mathrm{x})=1 \text { se } \mathrm{x}=1 \\
\mathrm{f}(\mathrm{x})=-\mathrm{x}+2 \text { se } \mathrm{x}>1\end{array}$ \\
\hline Odor & Médio & $\begin{array}{l}f(x)=x-1 \text { se } x<2 \\
f(x)=1 \text { se } x=2 \\
f(x)=-x+3 \text { se } x>2\end{array}$ \\
\hline Odor & Fresco & $\begin{array}{l}f(x)=x-2 \text { se } x<3 \\
f(x)=1 \text { se } x=3 \\
f(x)=1 \text { se } x>3\end{array}$ \\
\hline
\end{tabular}

\section{FUNCIONAMENTO DO SISTEMA}

Para um completo entendimento do PAQPesc, esta seção apresenta como o usuário pode utilizar o sistema corretamente e apresenta as telas existentes. Quando o sistema é aberto, o software apresenta a tela representada na Figura 2. Nela, o usuário tem acesso a todas as outras telas do sistema, e pode navegar de maneira aleatória, ou seja, não existe uma seqüência a ser seguida pelo usuário.

A seguir são apresentadas as ações necessárias para que um usuário cadastre um tipo de espécie. O usuário deve possuir login e senha já determinada na instalação do sistema de forma que ele possa efetuar a autenticação e iniciar a utilização cadastrando os tipos das espécies que serão avaliadas. Para isso, basta que seja ativado o item Tipo da Espécie no menu lateral. Em seguida será exibida a tela representada na Figura 3. É necessário que seja 
digitado o tipo da espécie e que seja pressionado o botão Gravar Dados, caso queira armazenar este registro no banco de dados do sistema. Caso queira apagar o que digitou, o botão Limpar deve ser pressionado. O botão Excluir permite que o usuário apague os dados armazenados no banco de dados quando ele achar que não é mais necessário mantê-los. Esta tela também permite fazer consultas de tipos de espécie, para isso, é necessário que se digite a primeira ou as primeiras letras do tipo desejado e que se ative o botão Buscar. O sistema irá apresentar o registro mais semelhante com as letras inseridas na busca.

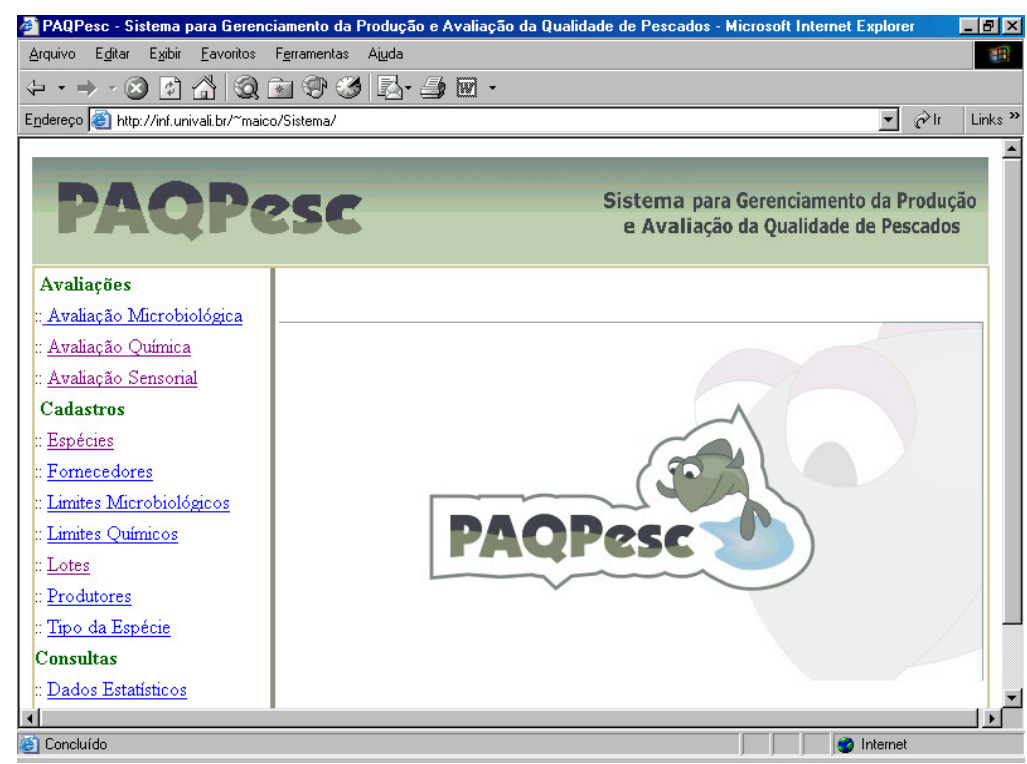

Figura 2. Tela Inicial do Sistema.

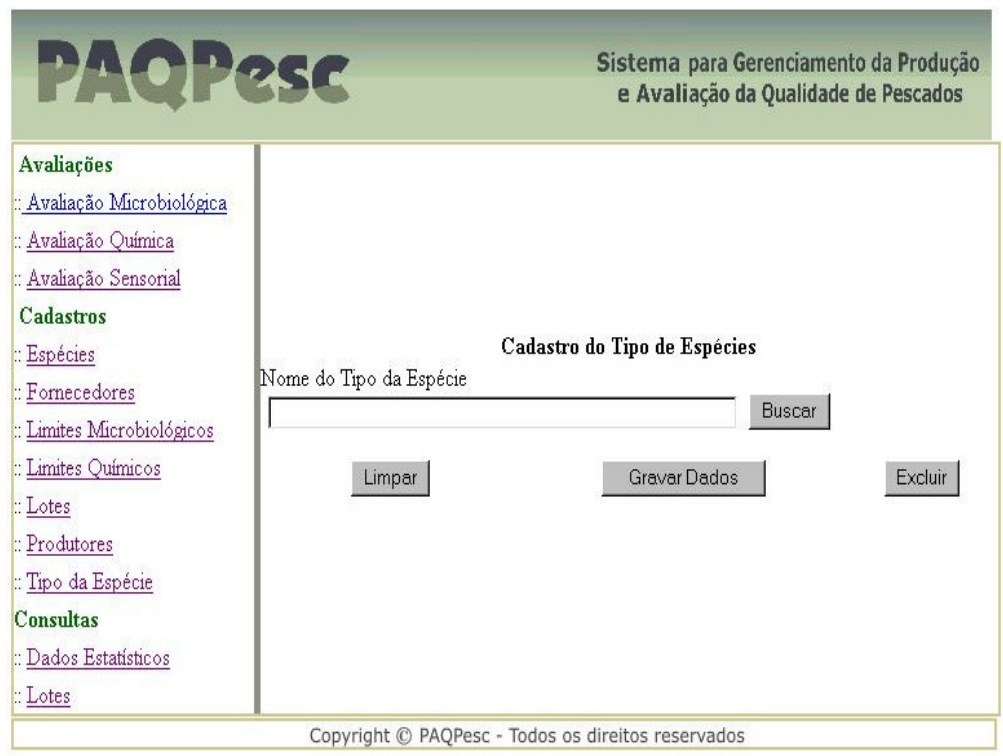

Figura 3. Cadastro de Tipo de Espécies. 
Um usuário que possua login e senha pode cadastrar espécies. Para isso, basta que seja ativado o item Espécies no menu lateral. Em seguida será exibida a tela apresentada na Figura 4. Após esta ação, é necessário que seja digitado o nome da espécie, e indicado o tipo da espécie. Apesar de que os limites químicos e microbiológicos das espécies são armazenados na própria tabela espécie, eles são cadastrados em telas diferentes.

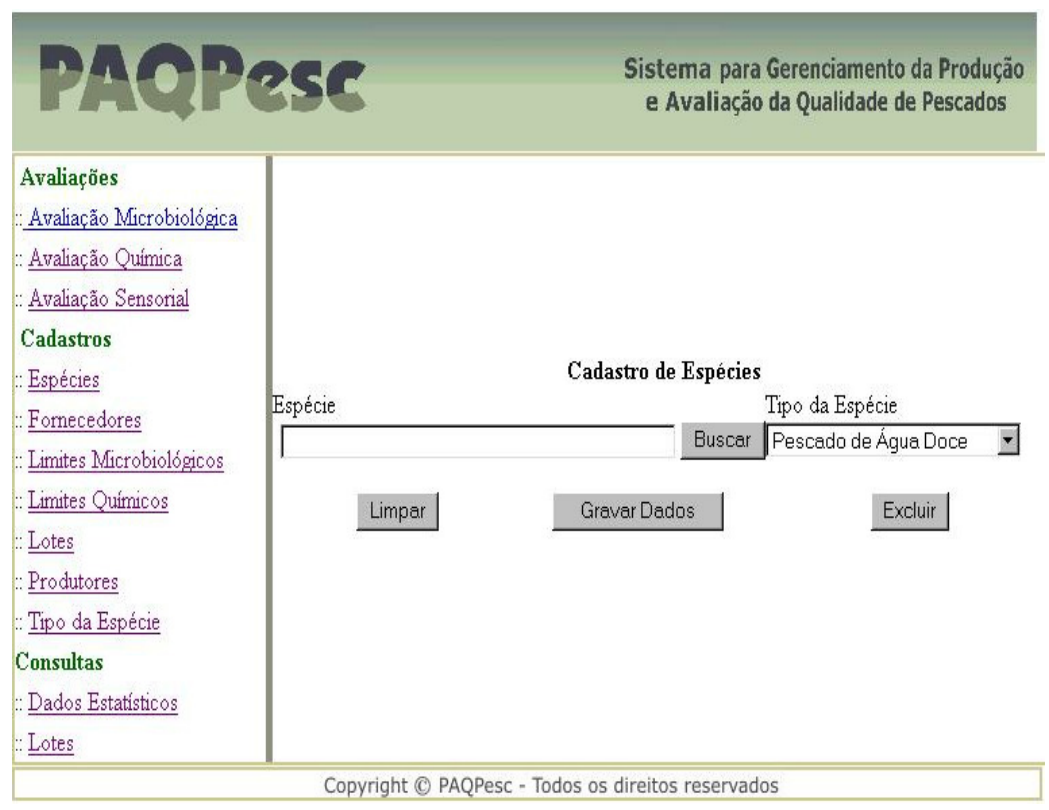

Figura 4. Cadastro de Espécies.

Um fornecedor é uma empresa que vende os pescados para a empresa que está utilizando o PAQPesc. Um usuário que possua login e senha pode cadastrar fornecedores. $\mathrm{O}$ procedimento correto para o cadastro de fornecedores é clicar no item Fornecedores no menu lateral. Em seguida será exibida a tela apresentada na Figura 5. À seguir, é necessário que o usuário insira os dados do fornecedor e utilize os botões existentes na tela para realizar a ação desejada. 


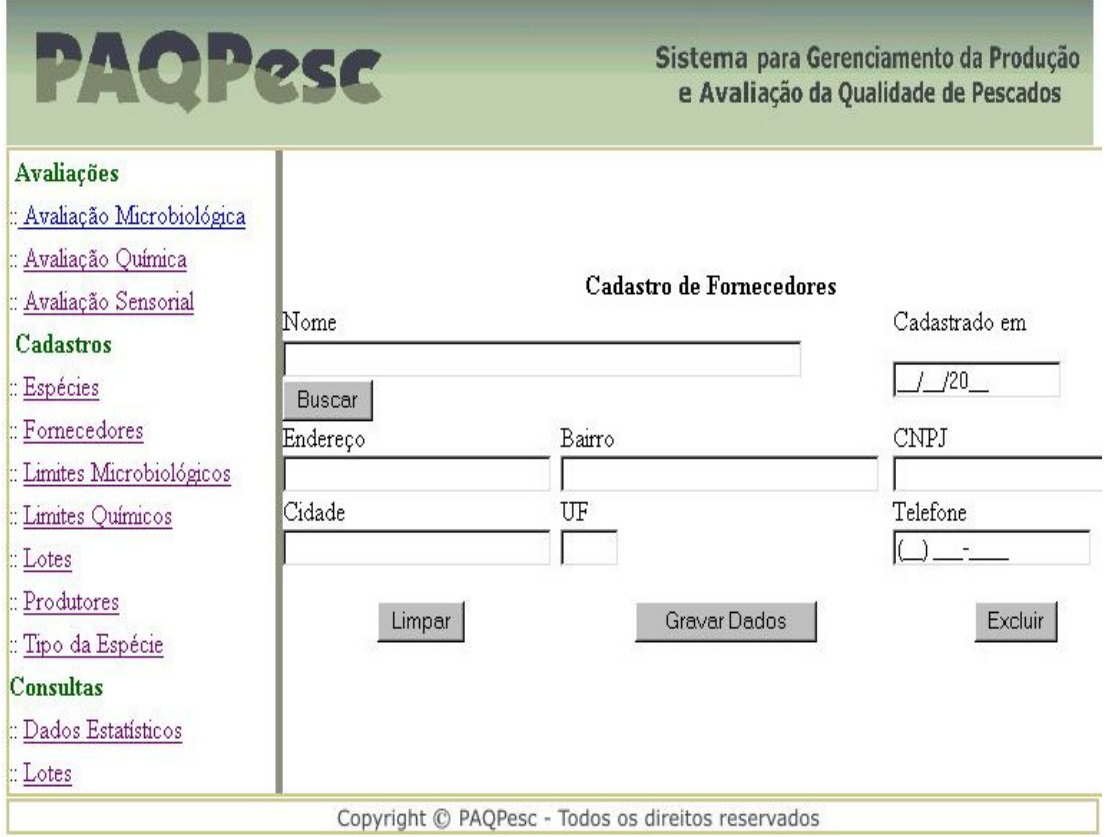

Figura 5. Cadastro de Fornecedores.

Um produtor é uma empresa que produz e muitas vezes também vende os pescados para a empresa que está utilizando o PAQPesc. Um usuário que possua login e senha pode cadastrar produtores. O procedimento para o cadastro de produtores é clicar no item Produtores no menu lateral. Em seguida será exibida a tela apresentada na Figura 6. À seguir, é necessário que o usuário insira os dados do produtor e utilize os botões existentes na tela para realizar a ação desejada.

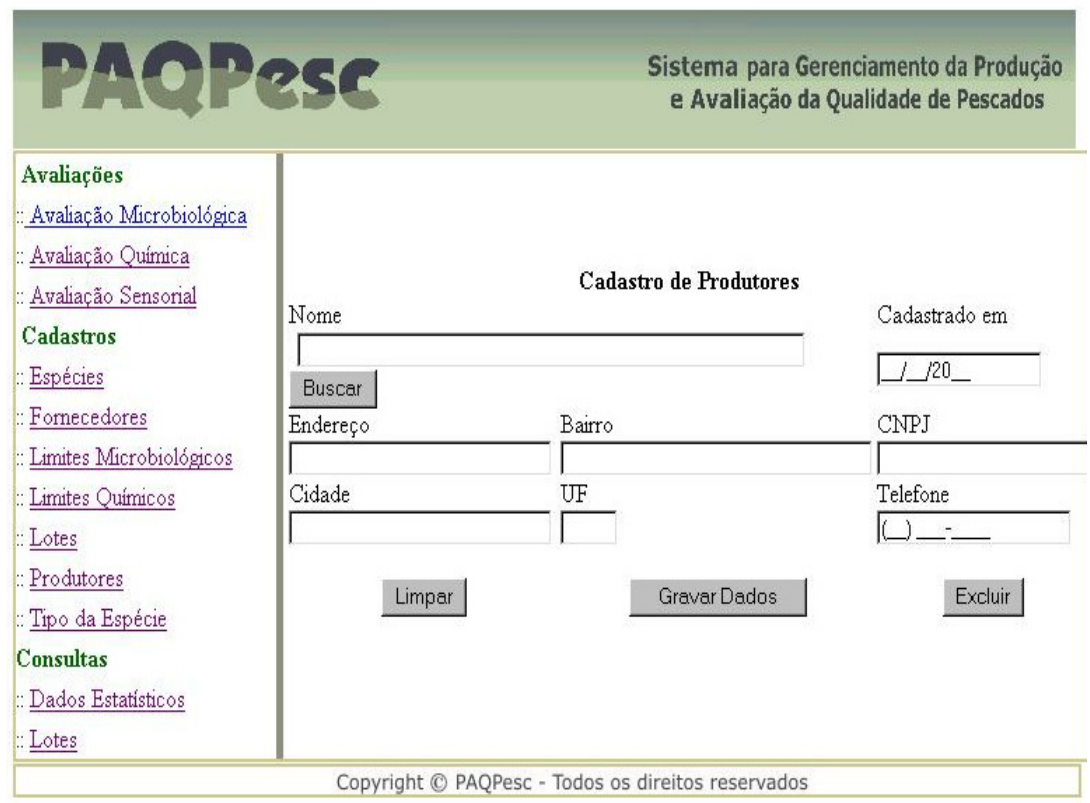

Figura 6. Cadastro de Produtores.

Revista Produção Online, Florianópolis, v.6, n.3,p.84, set./dez., 2006 
Quando a empresa utilizadora do PAQPesc compra os produtos pesqueiros para vender, ela adquire em lotes. Os lotes contêm informações como data de pesca e local, além de indicarem quem são os produtores e fornecedores, para eventuais consultas. $\mathrm{O}$ cadastro do lote é importante, pois sem ele não é possível cadastrar o resultado das análises de qualidade. Para realizá-lo, é necessário um usuário com identificação no sistema e este precisa clicar no item Lotes no menu lateral, conseqüentemente a tela apresentada na Figura 7 será exibida.

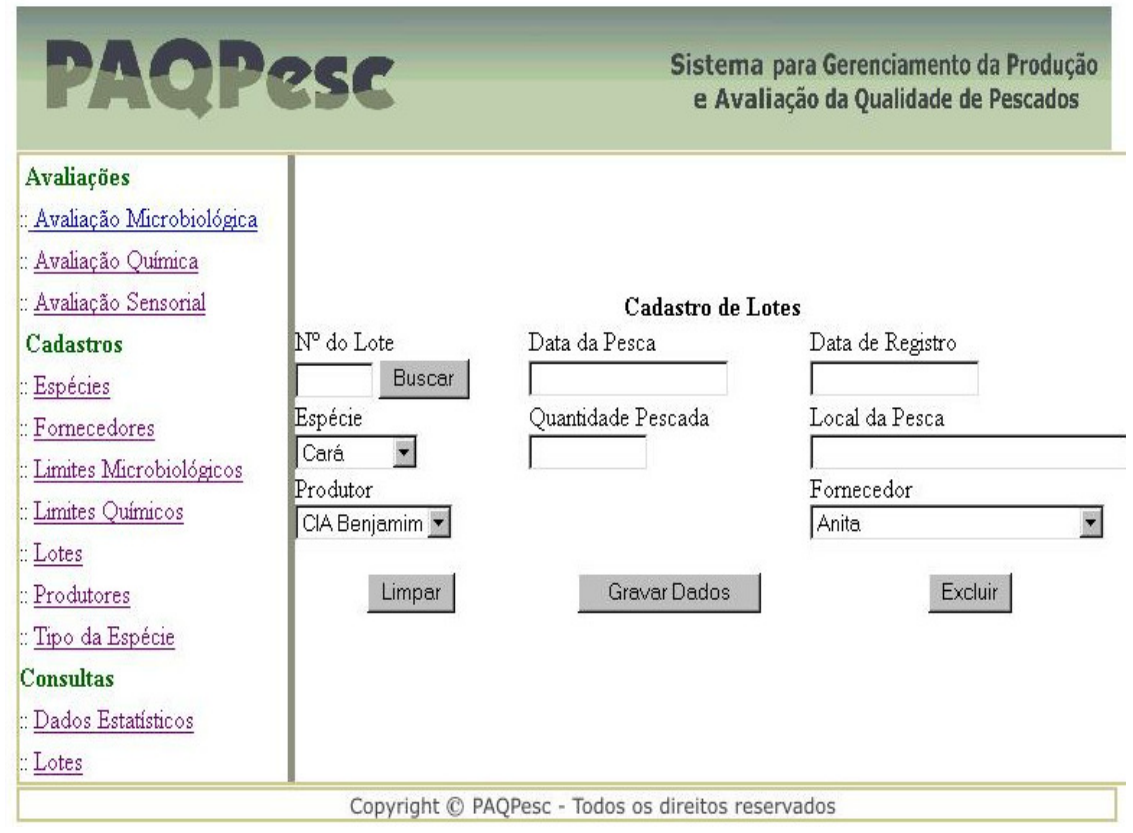

Figura 7. Cadastro de Lotes.

Os limites químicos de uma espécie são cadastrados na tela apresentada na Figura 8. Para acessá-la, o usuário precisa estar habilitado no sistema e deve clicar sobre o item Limites Químicos no menu lateral. Os dados inseridos nesta tela serão armazenados na tabela espécie. Portanto, quando o usuário desejar cadastrar um limite químico, é necessário que a espécie a qual os limites se referem já esteja cadastrada.

Os limites microbiológicos de uma espécie são cadastrados na tela apresentada na Figura 9. Para acessá-la, o usuário precisa estar habilitado no sistema e deve clicar sobre o item Limites Microbiológicos no menu lateral. Os dados inseridos nesta tela serão armazenados na tabela espécie. Portanto, quando o usuário desejar cadastrar um limite químico, é necessário que a espécie a qual os limites se referem já esteja cadastrada. 


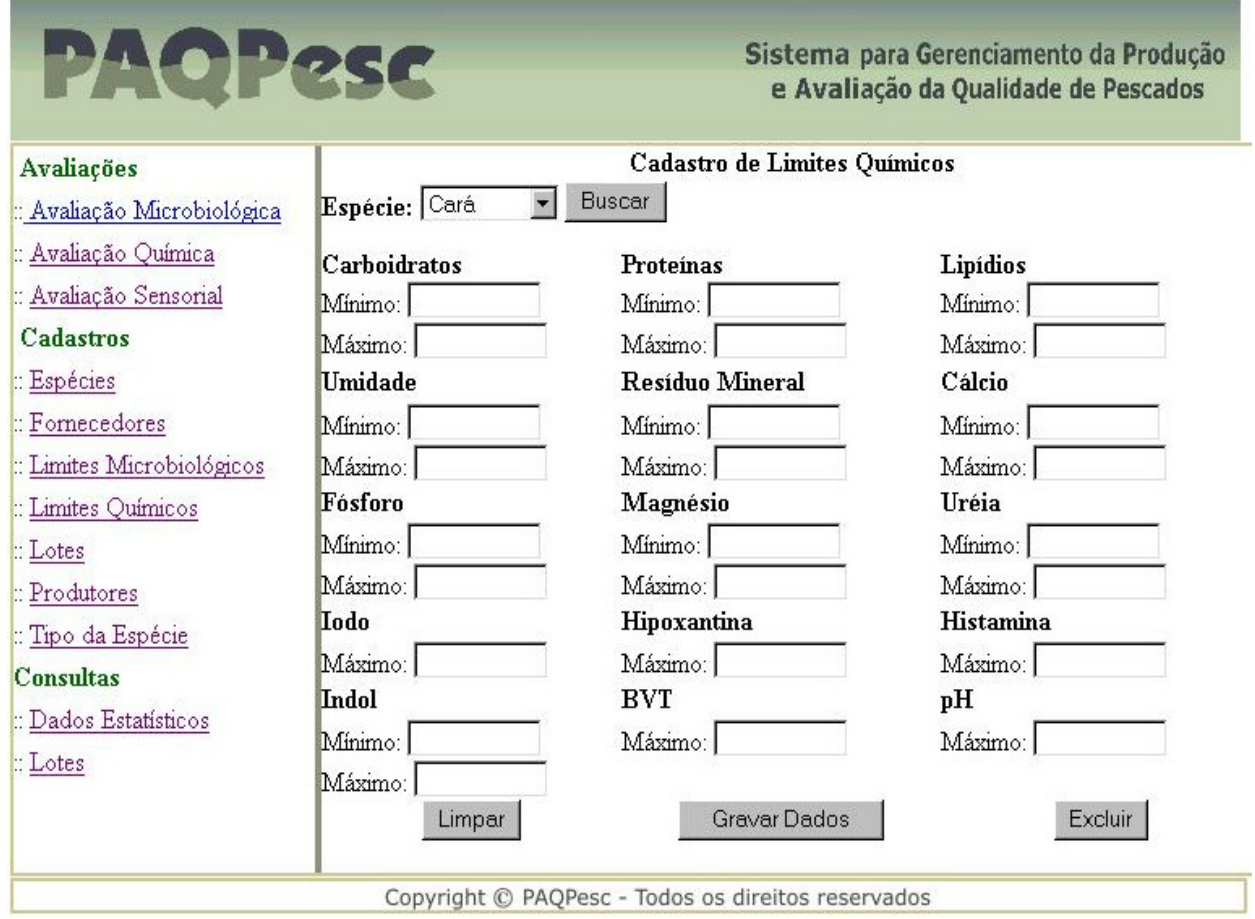

Figura 8. Cadastro de Limites Químicos.

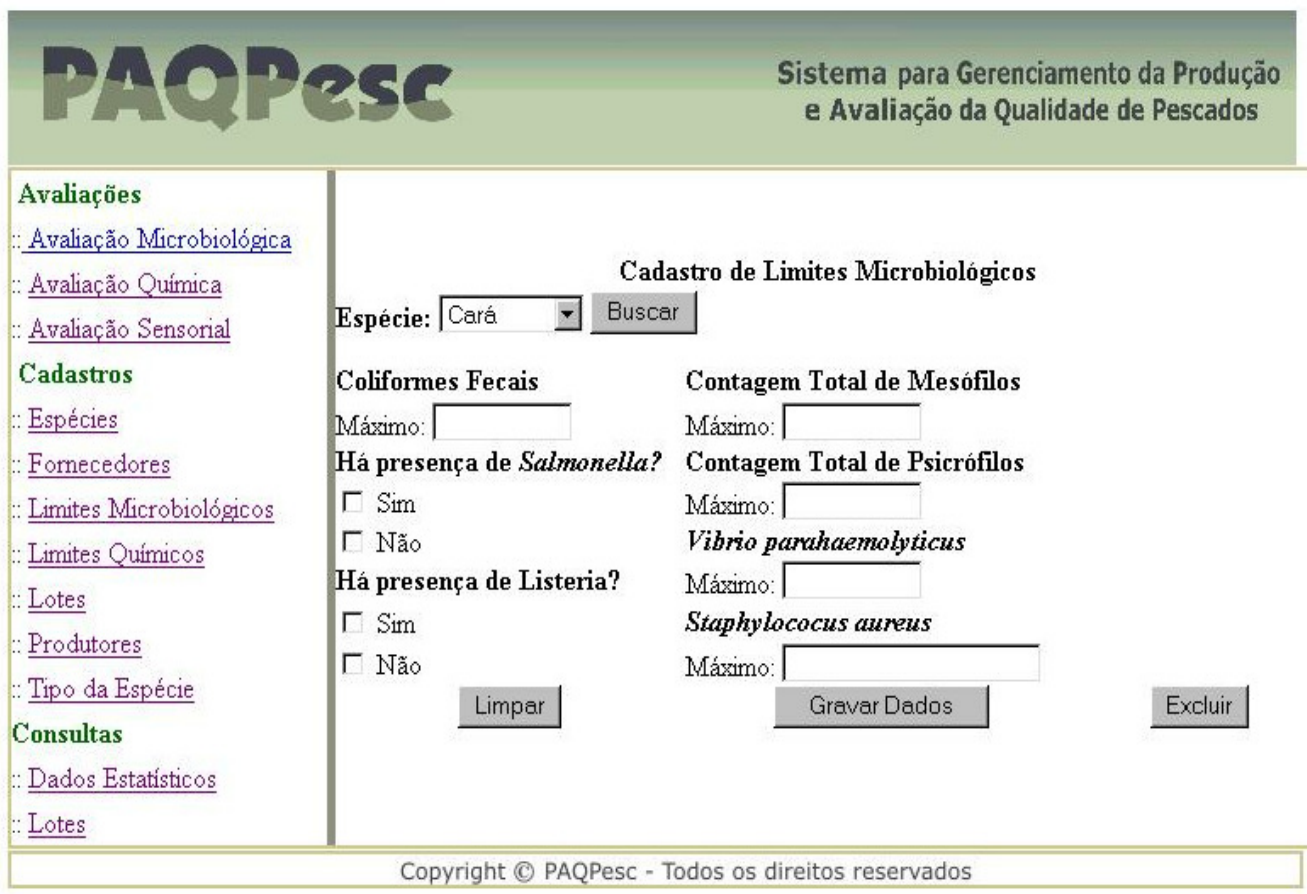

Figura 9. Cadastro de Limites Microbiológicos.

As análises químicas de uma espécie devem ser cadastradas após o registro desta espécie no sistema e também o registro do lote a ser avaliado. Ao escolher no menu lateral a opção Avaliação Química a tela apresentada na Figura 10 é exibida. O usuário deve estar 
identificado no sistema para poder fazer a inclusão dos dados. Estes dados são inseridos no banco de dados e quando é executada uma consulta de lotes, o sistema os utiliza para analisar a qualidade do pescado e formar um diagnóstico químico do lote avaliado.

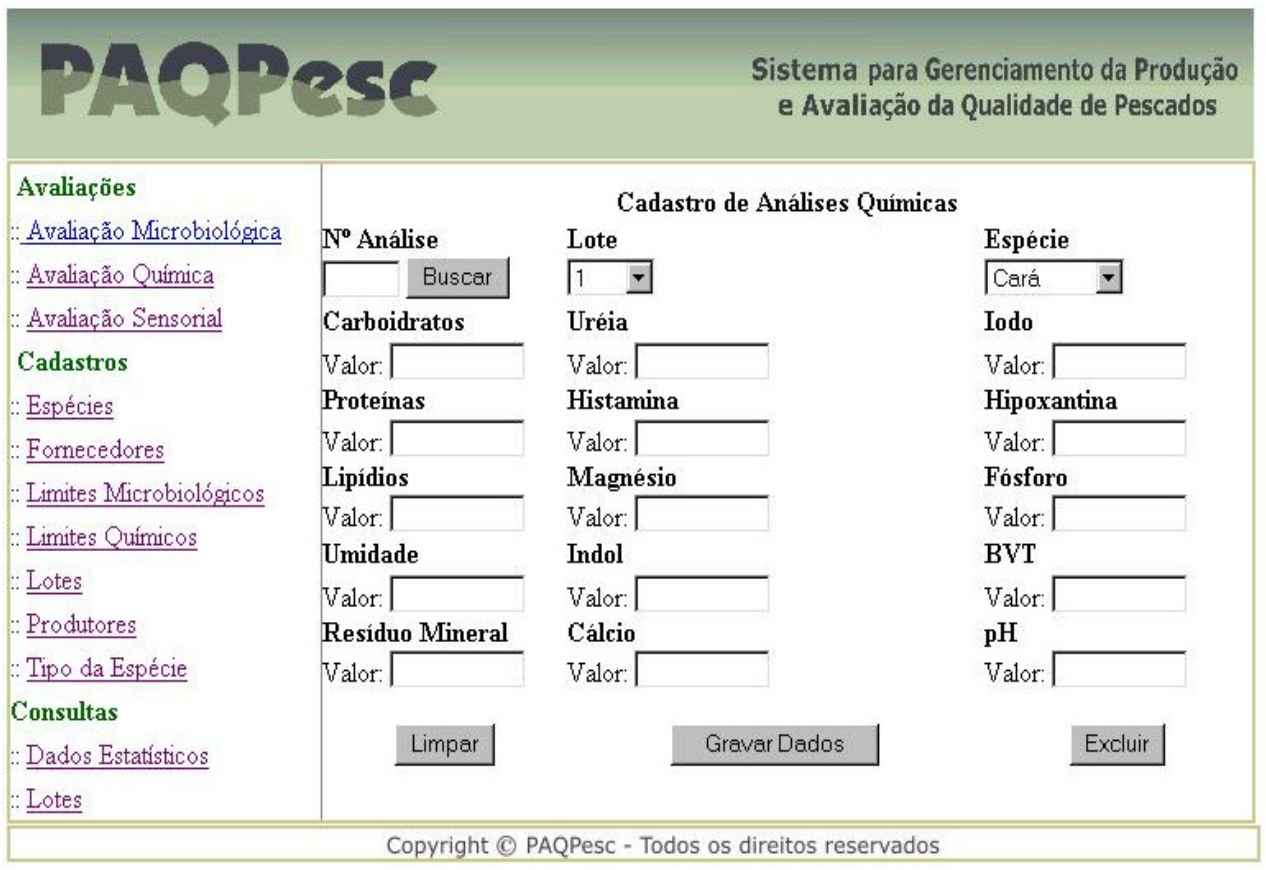

Figura 10. Cadastro de Análises Químicas.

As análises microbiológicas de uma espécie devem ser cadastradas após o registro desta espécie no sistema e também após o registro do lote a ser avaliado. Ao escolher no menu lateral a opção Avaliação Microbiológica a tela apresentada na Figura 11 é exibida. $\mathrm{O}$ usuário deve estar identificado no sistema para poder fazer a inclusão dos dados. Estes dados são armazenados no banco de dados do sistema e quando é solicitada uma consulta de lotes, o sistema os utiliza para analisar a qualidade do pescado e formar um diagnóstico microbiológico do lote avaliado. 


\begin{tabular}{|l|l|l|l|} 
Sistema para Gerenciamento da Produção \\
e Avaliação da Qualidade de Pescados
\end{tabular}

Figura 11. Cadastro de Análises Microbiológicas.

As análises sensoriais de uma espécie devem ser cadastradas após o registro desta espécie no sistema e também o registro do lote a ser avaliado. Ao escolher no menu lateral a opção Avaliação Sensorial a tela apresentada na Figura 12 é exibida. O usuário não precisa estar logado no sistema para poder fazer a inclusão dos dados sensoriais. Estes dados são gravados no banco de dados e quando é solicitada uma consulta de lotes, o sistema os utiliza para analisar a qualidade do pescado e formar um diagnóstico químico do lote avaliado.

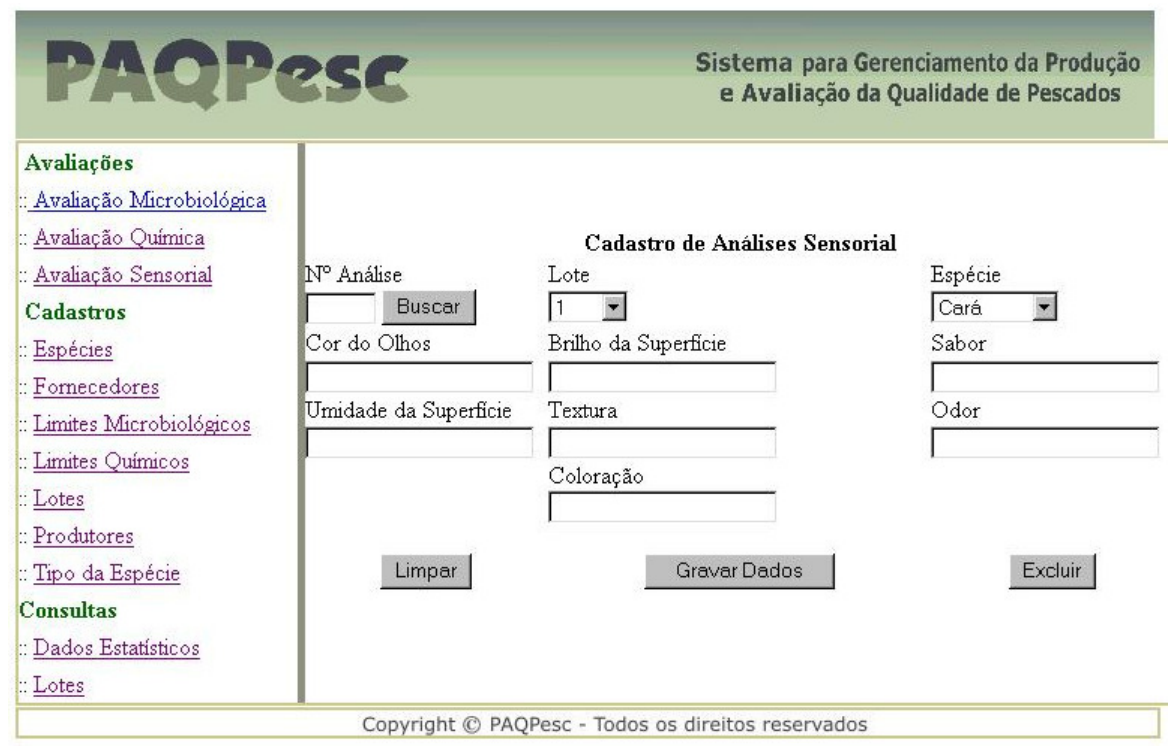


Figura 121. Cadastro de Análises Sensoriais.

A Figura 13 apresenta a tela da consulta de dados estatísticos. Nela é possível informar o lote que se deseja avaliar e que já está armazenado no sistema e solicitar uma consulta onde o sistema apresenta o fornecedor do referido lote e informa o percentual de vezes que houve problemas com os lotes adquiridos deste fornecedor. Para utilizar esta tela, o usuário não precisa estar identificado no sistema.

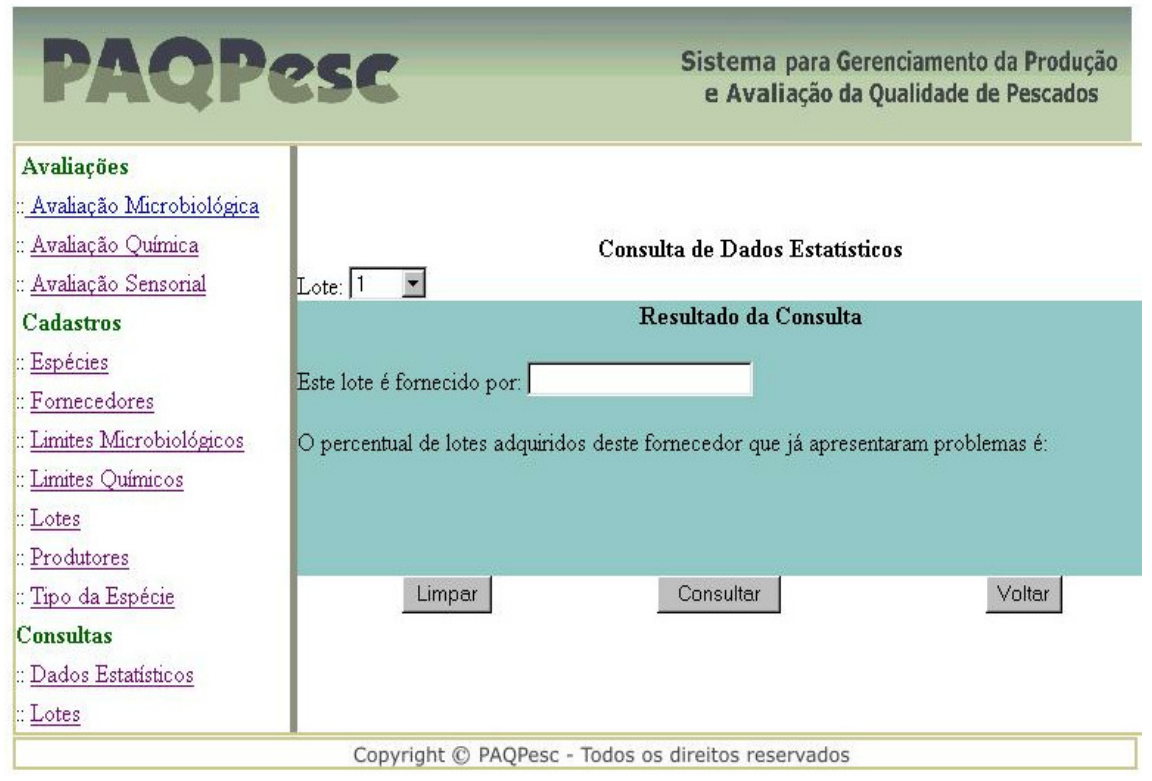

Figura 13. Consulta de Dados Estatísticos.

A Figura 14 exibe a tela da consulta de lotes. Nela é possível informar o lote que se deseja avaliar e que já está armazenado no sistema e solicitar uma consulta. Nesta tela, o usuário pode escolher qual das três análises deseja incluir no diagnóstico final, ou se desejar pode ainda escolher as três opções ou qualquer combinação entre elas. O PAQPesc se encarrega de analisar as avaliações armazenadas no banco de dados que possuam o mesmo número de lote e retornará um diagnóstico que será exibido na tela. 


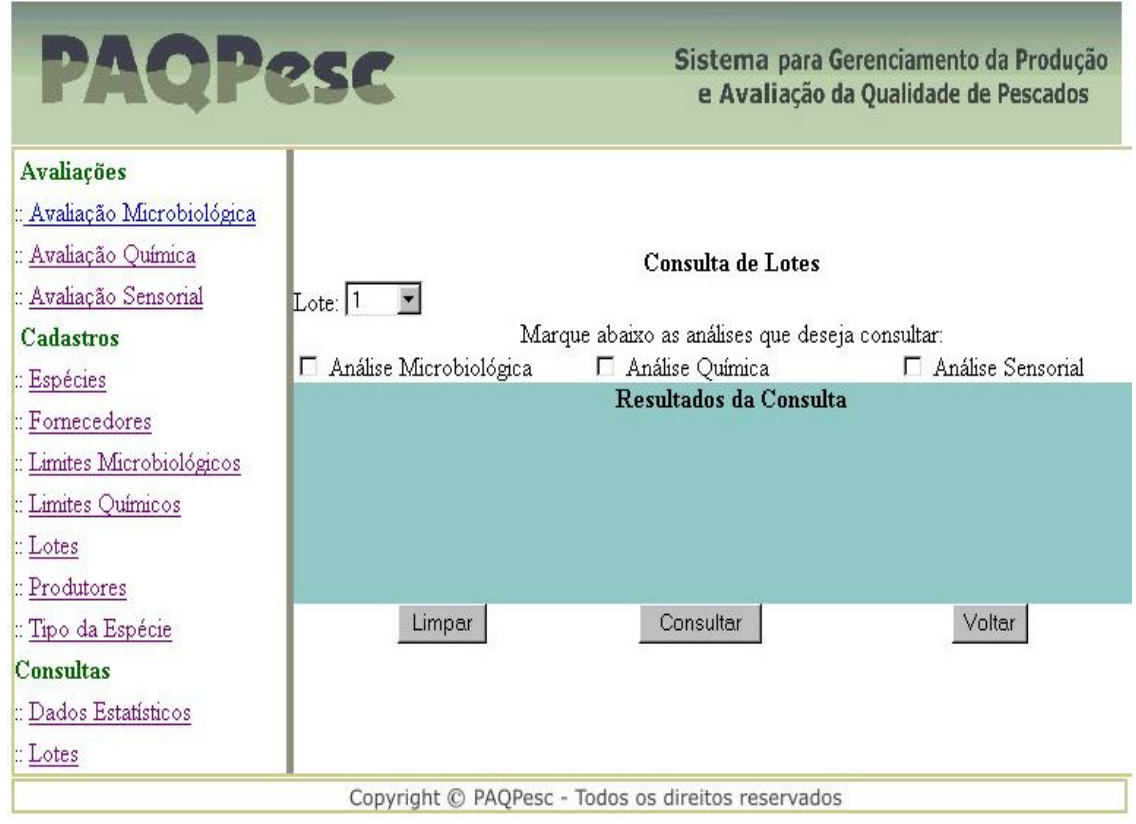

Figura 14. Consulta de Lotes.

\section{AVALIAÇÃO E TESTE DO SISTEMA}

Foi realizado um teste para avaliar a ergonomia do software, ou seja, avaliar se a interface do sistema é amigável ao usuário. Além deste teste, o sistema foi validado por um especialista biotecnológico, ou seja, verificou-se através desta validação, se o sistema estava apresentando resultados dentro do esperado. A seguir, tem-se o detalhamento do teste ergonômico e a validação do sistema.

\section{Teste Ergonômico}

O sistema foi testado ergonomicamente através de um questionário entregue à diversos usuários. Entre as pessoas que avaliaram o sistema, estavam usuários totalmente leigos (28 pessoas) e usuários que possuíam conhecimento sobre a funcionalidade e o objetivo do sistema (17 pessoas). O teste foi aplicado entre os dias 27 de outubro de 2004 e 01 de novembro de 2004. Nesse período, 45 pessoas utilizaram e testaram a ergonomia e a usabilidade do software. Ao responder o questionário as pessoas se identificaram e indicaram também o grau de instrução, porque foi aplicado a diversas faixas etárias e de escolaridade. A 
importância da escolaridade e da faixa etária é relacionada ao conhecimento que os usuários possuem sobre pescado. A seguir são apresentados os dados coletados do teste.

- Dos 45 usuários, 21 eram do sexo masculino e 24 do sexo feminino; 27 usuários tinham idade inferior à 20 anos, os outros 18 possuíam 20 anos ou mais; quanto à escolaridade, 5 estavam entre a $5^{\mathrm{a}}$ e a $8^{\mathrm{a}}$ séries, 10 possuíam o $2^{\circ}$ grau em andamento, 5 possuíam o $2^{\circ}$ grau completo, 20 estavam cursando o superior e apenas 5 usuários possuíam curso superior completo;

- Na primeira pergunta, que verificava a existência de títulos bem destacados na parte superior de cada página do sistema, 41 usuários responderam que estavam bem destacados, outros 4 indicaram que não;

- Quanto à existência de informação indicando como digitar um dado no sistema, como por exemplo, ___ _ $/ 20 \ldots$, o resultado foi sim por todos os usuários;

- A pergunta que avaliou a existência de algum elemento específico para entrada de dados como o sinal gráfico ": obteve sim como resposta por todos os usuários;

- A pergunta: a navegação do sistema é fácil? Trouxe como resposta sim por todos os usuários; o mesmo aconteceu ao responderem não na pergunta: você encontrou dificuldades para utilizar o PAQPesc?; a avaliação do menu de opções, obteve resposta unâmine como sim, indicando que está bem organizado;

- Os usuários foram questionados quanto ao conjunto de cores utilizado, onde 39 responderam que foi escolhido adequadamente, e outros 6 indicaram que não. Dos 6 que responderam não, 4 indicaram que a cor predominante deveria ser azul, por se tratar de um software que analisa produtos pesqueiros; e a última pergunta, que analisou os destaques de títulos e subtítulos, obteve resposta de 42 pessoas como sim, indicando que o destaque era suficiente e outras 3 como não.

\section{Validação do Sistema}

A validação do sistema foi realizada pelo especialista que auxiliou o desenvolvimento do sistema e por pessoas ligadas ao ramo biotecnológico. Eles utilizaram o sistema e responderam as questões solicitadas com um grau de satisfação onde 1 é o mínimo e 5 o valor máximo. As questões e as respostas dos usuários que validaram o sistema são apresentadas a seguir: 
As variáveis químicas que o sistema aborda são suficientes para a análise da qualidade? Que outras variáveis você poderia indicar? Para estas perguntas, os usuários concordaram e apontaram estas variáveis como suficentes;

$>$ As variáveis microbiológicas que o sistema aborda são suficientes para a análise da qualidade? Que outras variáveis você poderia indicar? Foi sugerida a inclusão da variável Coliformes Totais;

$>$ Os aspectos sensoriais que o sistema aborda são bastante relevantes e de fácil análise? Para esta pergunta, foram sugeridas modificações na avaliação dos peixes, alterando o aspecto cor dos olhos para o formato dos mesmos. Também sugeriu-se alterações nas abordagens das variáveis de forma que o sistema possua um objetivo melhor definido, fazendo com que o usuário tenha mais facilidade em responder as perguntas;

> O sistema interpreta os dados e mostra os resultados rapidamente? Os usuários responderam esta pergunta afirmando que o sistema é rápido;

$>$ As informações apresentadas na consulta de lotes onde é possível selecionar o tipo de análise a ser incluída no diagnóstico que o sistema gera, são suficientes? A resposta das pessoas que validaram o sistema foi sim;

$>\mathrm{O}$ sistema atende suas expectativas? As expectativas foram atendidas, mas muitas melhorias ainda podem ser implementadas no sistema visando melhorias na interface e na integração com o usuário comum; e

$>$ O software realiza o que foi proposto a fazer? O sistema construído realmente trata as informações corretame e possibilita que os objetivos traçados no início do projeto sejam alcançados.

\section{CONCLUSÕES}

Uma das características mais importantes do software desenvolvido é a possibilidade de flexibilidade dos limites microbiológicos e químicos. Isso permite que uma empresa trabalhe com um nível de qualidade maior do que o exigido pelas regras.

Como foi possível observar na seção de testes os objetivos previstos para este trabalho foram prontamente alcançados e a correta funcionalidade do sistema foi comprovada, assim como sua confiabilidade. Para que estes requisitos pudessem ser alcançados, foi necessária 
muita atenção no desenvolvimento do módulo inteligente do sistema, o qual avalia a qualidade do produto pesqueiro indicado. Sendo assim, comprova-se a grande utilidade das técnicas de inteligência artificial na implementação de soluções de software, que neste caso, possibilitaram o tratamento da imprecisão das respostas da análise sensorial de pescados e o tratamento das informações das avaliações químicas e microbiológicas nas árvores de decisão e regras de produção deste software. Na sessão de validação do sistema, pode ser observado a utilidade do sistema, nela comprova-se também que o PAQPesc realmente é um software que executa os objetivos projetados na fase inicial do trabalho.

Como considerações futuras, é interessante destacar que na análise sensorial a avaliação do aspecto cor dos olhos, deve se alterada para formato do olho. Dessa forma, se faz necessário novos estudos para definição das funções de pertinência e dos parâmetros utilizados pelo PAQPesc. Também na análise sensorial, é importante ressaltar a possibilidade de implantação de um mecanismo que faça a avaliação de alguns aspectos sensoriais dos pescados automaticamente através da técnica de reconhecimento de padrões. Com este mecanismo, a capacidade e a confiabilidade do sistema terão um aumento bastante considerável.

Este sistema pode ainda ser aperfeiçoado, adaptando-o para o gerenciamento da produção e avaliação de outros produtos do ramo alimentício. Basta para isso, que novas variáveis limitantes sejam pesquisadas e incorporadas no sistema.

Além disso, é necessário que sejam feitos testes com outras funções de pertinência além da triangular, a fim de melhor ajustar as regras fuzzy. Também, testes com especialistas em cada um dos produtos pesqueiros abordados pelo sistema seriam interessantes para um maior refinamento dos resultados.

\section{REFERÊNCIAS}

AGRIDATA. Pesquisa Agropecuária: pecuária-piscicultura. [S.1]:AGRIDATA, [200-]. Disponível em <http://www.agridata.mg.gov.br/pescado.htm>. Acesso em: 10 maio 2004.

BRUSCHI, F. L. F. Rendimento, composição química e perfil de ácidos graxos de pescados e seus resíduos: uma comparação. Itajaí, 2001. 68f. Trabalho de Conclusão de Curso (Graduação em Oceanografia)-Centro de Ciências Tecnológicas da Terra e do Mar, Universidade do Vale do Itajaí, Itajaí, 2001. 
ETALLCORP. Intensidade do crescimento de E. coli, Klebsiella sp e Staphylococcus aureus em função de temperaturas, $\mathrm{pH}$, pressão osmótica e concentração de oxigênio. [S.1]: ETALLCORP, 2001 .

Disponível

em:

<http://www.etall.hpg.ig.com.br/Docs/cresbac.doc>. Acesso em: 23 abr 2004.

FERNANDES, A. M. R. Inteligência Artificial: noções gerais. Florianópolis: Visual Books, 2003.

FERNANDES, E. S. QUALIPESC - Sistema inteligente para auxílio na avaliação da qualidade de pescados. Florianópolis, 2000. 81f. Dissertação de Mestrado (Engenharia de Produção) - Universidade Federal de Santa Catarina, Florianópolis, 2000.

GERMANO, M. I. S.; GERMANO, P. L.; OLIVEIRA, C. A. F. Aspectos da qualidade do pescado de relevância em saúde pública. São Paulo: Bicho on Line, 1998. Disponível em: <http://www.bichoonline.com.br/artigos/ha0016.htm>. Acesso em: 12 maio 2004.

KAI, M.; Controle de qualidade de pescado. São Paulo: Loyola, 1988. 303 p.

LUDORFF, W.; MEYER V. El pescado y los produtcos de la pesca. Zaragoza: Acribia, 1978.

MERCADO DA PESCA. Aqüicultura no Brasil. [S.1.]: Mercado da Pesca, [2003?]. Disponível em: <http://www.mercadodapesca.com.br/aquicultura01.php>. Acesso em: 16 mar. 2004.

OETTERer, M. O Processo de Fermentação do Pescado. São Paulo: USP, [2003?]. Disponível em: <http://www.esalq.usp.br/departamentos/lan/Download_arquivos.html>. Acesso em: 29 abr 2004.

REZENDE, S. O. Sistemas Inteligentes: fundamentos e aplicações. Barueri: Manole, 2003. $525 \mathrm{p}$. 
